\title{
Noncommunicable Diseases: Current Status of Major Modifiable Risk Factors in Korea
}

\author{
Hyeon Chang Kim', Sun Min Oh² \\ ${ }^{1}$ Department of Preventive Medicine, Yonsei University College of Medicine, Seoul; ${ }^{2}$ Medical Affairs, Novartis Korea Oncology, Seoul, Korea
}

\begin{abstract}
A noncommunicable disease (NCD) is a medical condition or disease that is by definition non-infectious and non-transmissible among people. Currently, NCDs are the leading causes of death and disease burden worldwide. The four main types of NCDs, including cardiovascular disease, cancer, chronic lung disease, and diabetes, result in more than 30 million deaths annually. To reduce the burden of NCDs on global health, current public health actions stress the importance of preventing, detecting, and correcting modifiable risk factors; controlling major modifiable risk factors has been shown to effectively reduce NCD mortality. The World Health Organization's World Health Report 2002 identified tobacco use, alcohol consumption, overweight, physical inactivity, high blood pressure, and high cholesterol as the most important risk factors for NCDs. Accordingly, the present report set out to review the prevalence and trends of these modifiable risk factors in the Korean population. Over the past few decades, we observed significant risk factor modifications of improved blood pressure control and decreased smoking rate. However, hypertension and cigarette smoking remained the most contributable factors of NCDs in the Korean population. Moreover, other major modifiable risk factors show no improvement or even worsened. The current status and trends in major modifiable risk factors reinforce the importance of prevention, detection, and treatment of risk factors in reducing the burden of NCDs on individuals and society.
\end{abstract}

Key words: Noncommunicable disease, Risk factors, Prevalence, Trend, Korea

\section{INTRODUCTION}

A noncommunicable disease (NCD) is a medical condition or disease that is by definition non-infectious and non-transmissible among people. NCDs have long been the leading causes of death in developed countries, but are no longer health issues limited to high income countries [1,2] . The World Health

Received: July 11, 2013; Accepted: July 19, 2013

Corresponding author: Hyeon Chang Kim, MD, PhD

50 Yonsei-ro, Seodaemun-gu, Seoul 120-749, Korea

Tel: +82-2-2228-1873, Fax: +82-2-392-8133

E-mail: hckim@yuhs.ac

This is an Open Access article distributed under the terms of the Creative Commons Attribution Non-Commercial License (http://creativecommons.org/licenses/by$\mathrm{nc} / 3.0 / /)$ which permits unrestricted non-commercial use, distribution, and reproduction in any medium, provided the original work is properly cited.
Organization (WHO) reports and many international statistics indicate that NCDs are the global leading cause of death. According to the WHO's Global Health Observatory data, NCDs resulted in 36 million deaths (63\% of 57 million deaths total) in 2008 [3]. Alarmingly, NCDs are now the leading causes of death in most low-income and middle-income countries. More seriously, NCD burden is increasing more rapidly in lower income countries and populations. In 2008, four fifths of NCD deaths occurred in low- and middle-income countries, and one third of these deaths killed people aged less than 60 years [4]. The four main types of NCDs are cardiovascular diseases, cancers, chronic lung diseases, and diabetes, leading to $17 \mathrm{mil}-$ lion, 7.6 million, 4.2 million, and 1.3 million deaths, respectively, in 2008 [3]. Accordingly, most public health actions have targeted modifiable risk factors to reduce the burden of NCDs, as preventing or treating major modifiable risk factors has 
proven to be effective in reducing mortality from NCDs. The WHO's World Health Report 2002 identified tobacco use, alcohol consumption, overweight, physical inactivity, high blood pressure, and high cholesterol as important risk factors for NCDs [5]. In accordance therewith, the present report set out to review the prevalence and trends of these six modifiable risk factors in the Korean population.

\section{TOBACCO USE}

Cigarette smoking has long been the greatest cause of NCDs in Korea. Previously, the population attributable risks due to smoking were estimated as $73 \%$ for lung cancer mortality, $32 \%$ for stomach cancer mortality, $15 \%$ for liver cancer mortality and $24 \%$ for pancreas cancer mortality [6]. An additional study reported that smoking attributed to $41 \%$ of coronary heart diseases and $26 \%$ of strokes in Korean men [7]. Korean data indicate that cigarette smoking is a major modifiable risk factor for type 2 diabetes: smoking is associated with diabetes incidence and mortality [8], and smoking cessation has been shown to reduce the risk for developing diabetes among smokers [9]. Additionally, smoking is the most contributable factor in the development and progression of chronic lung disease [10-12].

Among Korean adult males, smoking rates have decreased from $79 \%$ in 1980 to $67 \%$ in 1998 and $45 \%$ in 2007, but have not decreased any further since. Smoking rates in adult fe-

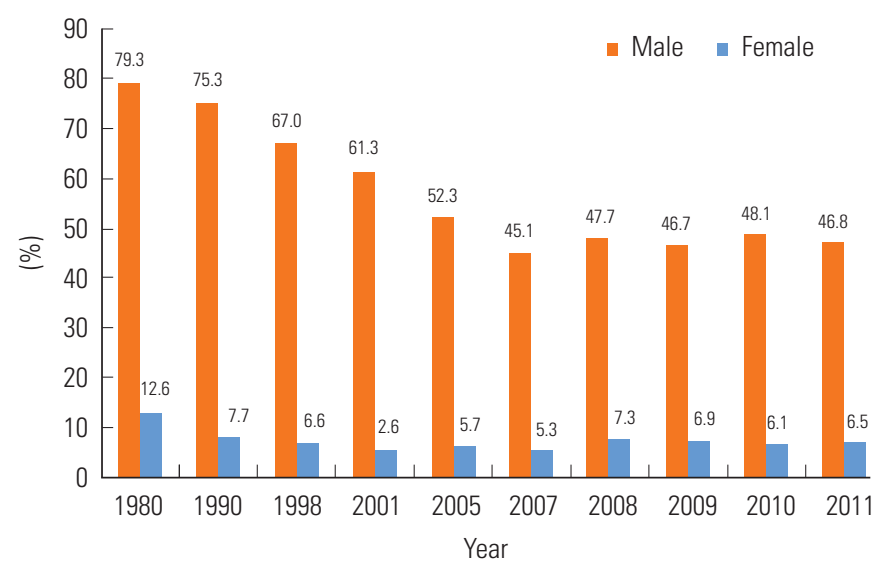

Figure 1. Proportion of current smokers among Korean adults aged 19 years or older. Modified from Korea Centers for Disease Control and Prevention. Korea health statistics 2011: Korea National Health and Nutrition Examination Survey (KNHANES V-2). Seoul: Ministry of Health and Welfare; 2012 [13]. males have not seen much change (Figure 1). According to the latest Korea National Health and Nutrition Examination Surveys (KNHANES) report, the smoking rate was $47 \%$ in male adults and $6.5 \%$ in female adults [13]. However, in a 2008 survey, smoking rates verified by urinary cotinine level were much higher, at $50 \%$ for male and $14 \%$ for female adults [14]. Reports have also indicated that smoking rates differ by age and socio-economic status. Among men, smoking rates were highest in those in their 30s, while among women, smoking rates were highest in those in their 20s. Lower household income was also associated with a higher smoking rate in both men and women, but this association was stronger in women: smoking rate was $4 \%$ in women of the highest income quartile, but $11 \%$ in those of the lowest income quartile [13].

\section{ALCOHOL CONSUMPTION}

Alcohol consumption is associated with increased risks of chronic liver disease, heart failure, and some types of malignancy [15-17]. Although moderate alcohol consumption has been shown to be associated with reduced cardiovascular incidence and mortality, excessive alcohol consumption is associated with elevated blood pressure and thus hemorrhagic types of stroke $[18,19]$. Moreover, increasing evidence supports that there is no threshold in the adverse effects of alcohol on the risk of cancer and other chronic diseases [20,21]. For these reasons, alcohol drinking of more than one drink per day

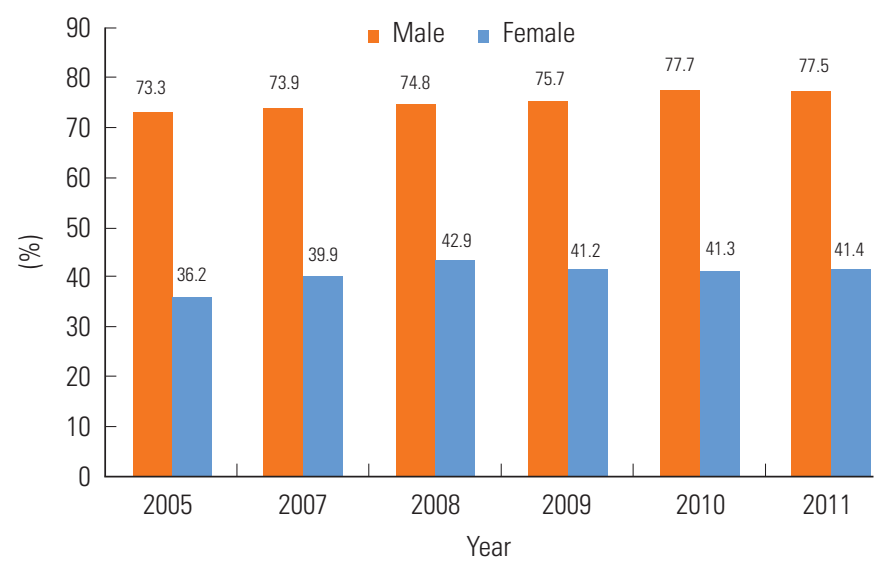

Figure 2. Proportion of people who drink at least once a month among Korean adults aged 19 years or older. Modified from Korea Centers for Disease Control and Prevention. Korea health statistics 2011: Korea National Health and Nutrition Examination Survey (KNHANES V-2). Seoul: Ministry of Health and Welfare; 2012 [13]. 
is not recommended for the purpose of disease prevention.

According to the 2011 KNHANES report, $78 \%$ of male and $41 \%$ of female adults aged 19 years or older drink alcohol at least once a month (Figure 2). At risk drinking is highly frequent among both male and female Korean adults: $26 \%$ of adult males intake 7 or more drinks at least twice a week and $6 \%$ of adult females intake 5 or more drinks at least twice a week, the prevalence of which showed a slightly increasing trend (Figure 3) [13]. Among alcoholic drinkers, 38\% were classified into harmful categories based on Alcohol Use Disorders Identification Test: $24 \%$ for hazardous drinking, $7 \%$ for alcohol abuse, and $8 \%$ for alcohol dependence [13,22].

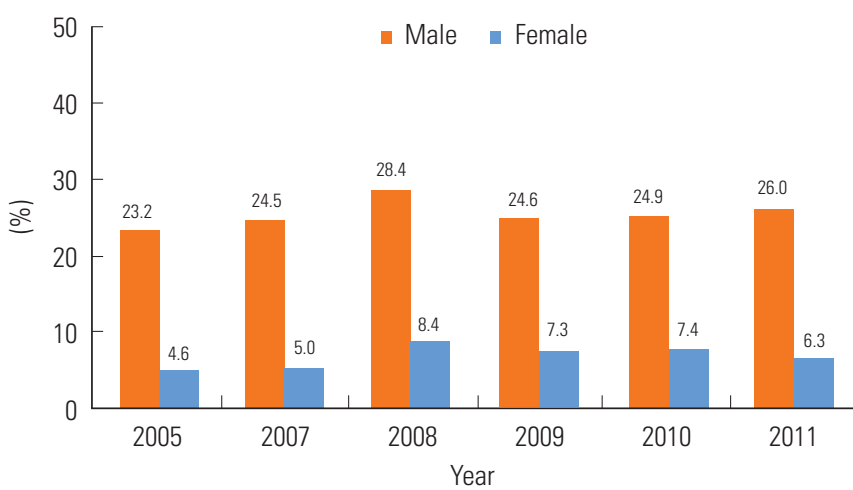

Figure 3. Proportion of people who reported at risk drinking among Korean adults aged 19 years or older. ${ }^{1}$ At risk drinking: intake 7 or more drinks ( 5 or more in women) at least twice a week. Modified from Korea Centers for Disease Control and Prevention. Korea health statistics 2011: Korea National Health and Nutrition Examination Survey (KNHANES V-2). Seoul: Ministry of Health and Welfare; 2012 [13].

\section{OVERWEIGHT AND OBESITY}

Being overweight or obese is an important risk factor for all four major NCDs including cardiovascular disease, cancer, diabetes, and chronic lung disease. Moreover, obesity is a wellknown risk factor of diabetes and insulin resistance. The prevalences of obesity and diabetes are increasing concomitantly in Korea $[23,24]$. Presumably, the population attributable risk of obesity in cardiovascular disease is increasing, as obesity itself is on the rise and the major forms of cardiovascular disease have changed from hemorrhagic stroke to ischemic stroke and coronary heart disease in Korea. The impact of obesity is also garnering greater attention among cancer prevention efforts as well. Colorectal cancer and female breast cancer are increasing as two major causes of cancer death $[25,26]$, and obesity is a major modifiable risk factor of these two malignancies. Additionally, there is increasing evidence that obesity and chronic lung disease are inter-related [27].

Currently, about one third of Korean adults have a body mass index (BMI) higher than $25.0 \mathrm{~kg} / \mathrm{m}^{2}$. Between 1998 and 2011 , the prevalence of a high BMI $\left(\geq 25.0 \mathrm{~kg} / \mathrm{m}^{2}\right)$ increased from $29 \%$ to $34 \%$ among adults aged 30 years or older. During the same period, the prevalence of a high BMI increased from $15 \%$ to $22 \%$ among people aged 19 to 29 years old [13]. Similarly in many other developed countries, being overweight increased more steeply among low-income people than highincome people.

One unique feature in the trends of obesity in Korea is a discrepancy between men and women. Between 1998 and 2011, the age-standardized prevalence of high BMI increased by

- Lower 25\% - -Lower middle - Upper middle - Upper $25 \%$
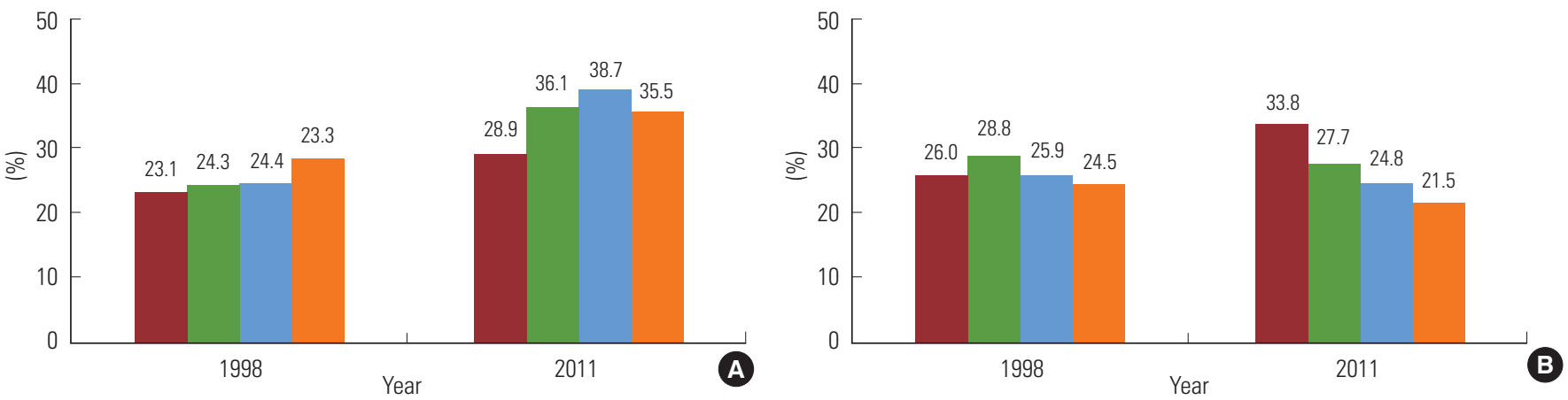

Figure 4. Age-adjusted prevalence of obesity by quartiles of household income. Male (A) and female (B) adults aged 19 years or older. Obesity is defined as body mass index $\geq 25 \mathrm{~kg} / \mathrm{m}^{2}$. Modified from Korea Centers for Disease Control and Prevention. Korea health statistics 2011: Korea National Health and Nutrition Examination Survey (KNHANES V-2). Seoul: Ministry of Health and Welfare; 2012 [13]. 
$1.1 \%$ per year in men, but decreased by $0.1 \%$ per year in women [13]. Interestingly, obesity trends were affected by household income in a different manner between men and women (Figure 4). Obesity increased in men of all income categories, although the increase was slightly greater in men of lower household income. On the contrary, the prevalence of a high BMI increased greatly from $26 \%$ to $34 \%$ in women of the lowest income quartile, but decreased from $25 \%$ to $22 \%$ in women of the highest income quartile [13].

\section{PHYSICAL INACTIVITY}

Physical inactivity is the fourth leading risk factor for mortal-

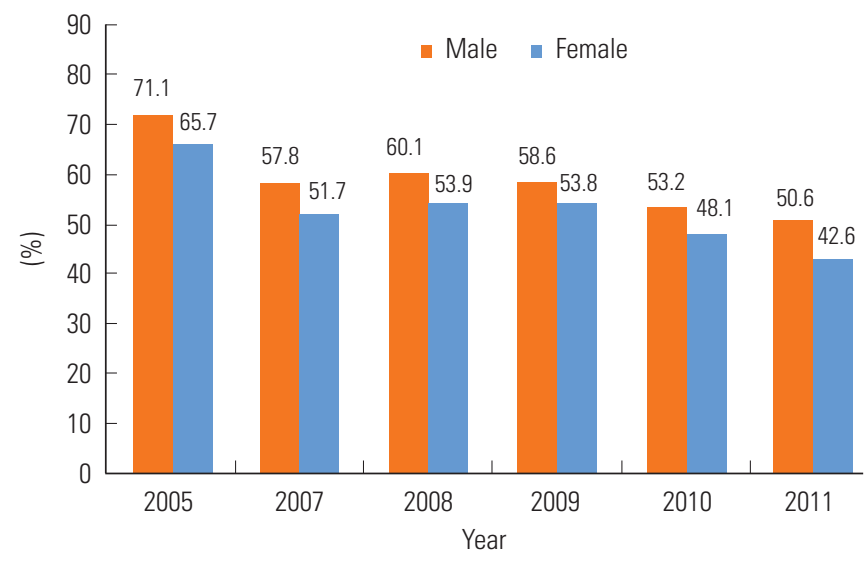

Figure 5. Proportion of people who exercise at moderate to high intensity (including walking) among Korean adults aged 19 years or older. Modified from Korea Centers for Disease Control and Prevention. Korea health statistics 2011: Korea National Health and Nutrition Examination Survey (KNHANES V-2). Seoul: Ministry of Health and Welfare; 2012 [13].

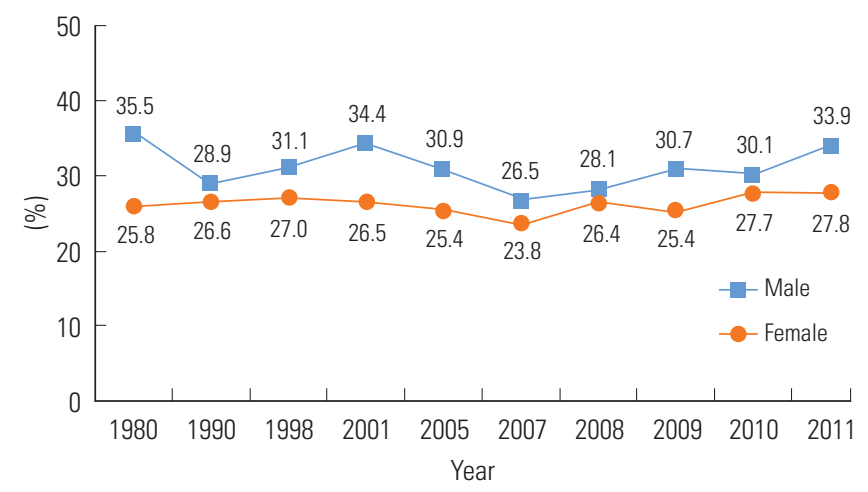

Figure 6. Prevalence of hypertension among Korean adults. Modified from Korea Centers for Disease Control and Prevention. Korea health statistics 2011: Korea National Health and Nutrition Examination Survey (KNHANES V-2). Seoul: Ministry of Health and Welfare; 2012 [13]. ity [28], and it has been shown to be associated with cardiovascular [29,30] and cancer mortality [31], as well as all-cause mortality [32]. In addition, physical inactivity is a known risk factor for obesity, metabolic syndrome [33], and cardiovascular disease [34]. Korean data also suggests that increased levels of physical activity are significantly associated with a decreased risk of abnormal components of metabolic syndrome $[35,36]$.

According to the KNHANES report, the percentage of Koreans who exercised at moderate-to-high intensity, including walking, significantly decreased in both Korean men (from $71.4 \%$ in 2005 to $50.6 \%$ in 2011) and women (from $65.7 \%$ in 2005 to $42.6 \%$ in 2011) (Figure 5) [13]. Physical inactivity also differed by age and sex. The highest amounts of physical activity were shown in both men and women in their 20s, while men in their 40s and women in their 70s or older showed the lowest amounts of physical activity [13].

\section{HIGH BLOOD PRESSURE}

High blood pressure is the most contributable risk factor of stroke, and one of the major risk factors of coronary heart disease [37-40]. Hypertension is closely associated with type 2 diabetes [41], even though it is unclear whether hypertension directly increases the risk of diabetes. There is some evidence, however, that supports that hypertension is associated with risk of certain types of cancer [42-44]. Prevention and control of hypertension may be the most urgent public health issue in Korea, as the prevalence of hypertension is relatively high and stroke is the leading cause of death among Koreans.

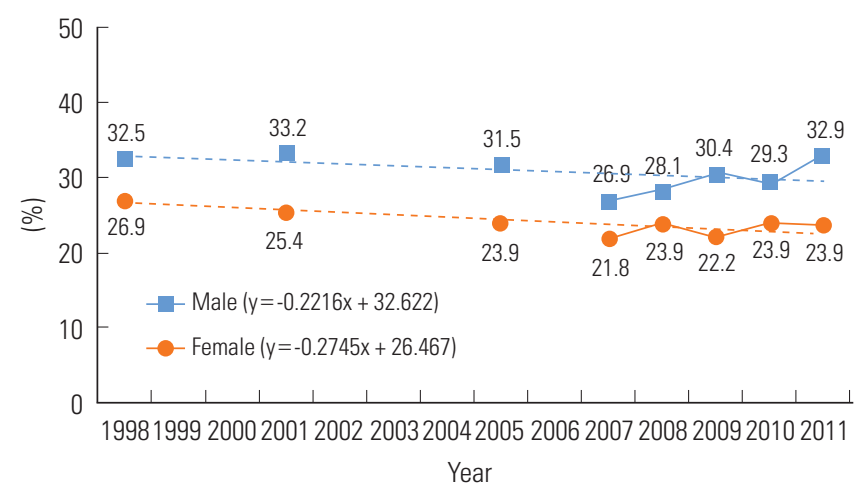

Figure 7. Age-adjusted prevalence of hypertension among Korean adults. Modified from Korea Centers for Disease Control and Prevention. Korea health statistics 2011: Korea National Health and Nutrition Examination Survey (KNHANES V-2). Seoul: Ministry of Health and Welfare; 2012 [13]. 




Figure 8. Trends in mean blood pressure level $(\mathrm{mmHg})$ among Korean adults. Modified from Korea Centers for Disease Control and Prevention. Korea health statistics 2011: Korea National Health and Nutrition Examination Survey (KNHANES V-2). Seoul: Ministry of Health and Welfare; 2012 [13].

SBP, systolic blood pressure; DBP, diastolic blood pressure.

According to early nationwide blood pressure studies in 1980 and $1990[45,46]$ and reports from the KNHANES since 1998 [13], the prevalence of hypertension in the Korean population did not change very much (Figure 6). Korea, however, is a rapidly aging society, in which the age-adjusted prevalence of hypertension actually shows a decreasing tendency. Analysis of data from the KNHANES 1998 through 2011 showed that the age-adjusted prevalence of hypertension decreased by 0.2 to 0.3 percent annually (Figure 7). More importantly, the population's mean blood pressure level has decreased continuously. Mean systolic blood pressure level decreased by $8 \mathrm{mmHg}$ in men and by $10 \mathrm{mmHg}$ in women, and mean diastolic blood pressure level by $3 \mathrm{mmHg}$ in men and by $4 \mathrm{mmHg}$ in women between 1998 and 2011 (Figure 8). This decrease in population blood pressure level was largely due to lowered blood pressure levels among patients with hypertension. Management of hypertension has been markedly improved in Korea during the past few decades. Among the patients with hypertension aged 30 years or older, awareness rates increased from $25 \%$ in 1990 to $67 \%$ in 2011 , treatment rates increased from $16 \%$ in 1990 to $61 \%$ in 2011 , and control rates increased from $1 \%$ in 1990 to $43 \%$ in 2011 [13].

These improvements in hypertension indexes have led to a dramatic decrease in stroke mortality. However, stroke remains the number one cause of death in Koreans, and hypertension control is still the biggest challenge to reducing the burden of NCDs. Although hypertension management has improved much in general, greater attention is needed concern-

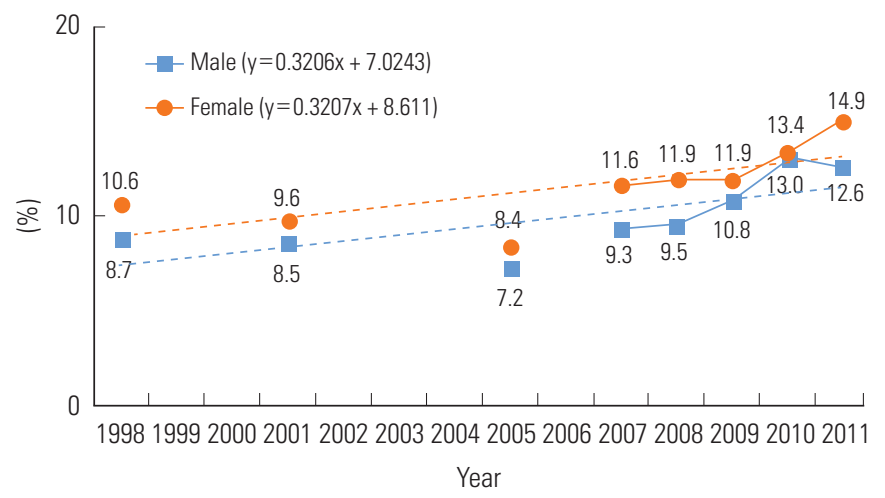

Figure 9. Age-adjusted prevalence of hypercholesterolemia among Korean adults. Modified from Korea Centers for Disease Control and Prevention. Korea health statistics 2011: Korea National Health and Nutrition Examination Survey (KNHANES V-2). Seoul: Ministry of Health and Welfare; 2012 [13].

ing subgroups. For example, awareness, treatment, and control rates are much lower in younger patients with hypertension than in older patients, while control rates within patients under treatment do not differ by age [13]. These imply that a lack of awareness is the main cause of uncontrolled hypertension among younger patients, and reinforce the importance of screening for elevated blood pressure earlier in life.

\section{HIGH BLOOD CHOLESTEROL}

High blood cholesterol level or hypercholesterolemia is a major risk factor of atherosclerotic cardiovascular diseases including coronary heart disease and ischemic stroke, as well as peripheral arterial disease [47]. High cholesterol level has been reported to be associated with certain types of malignancy including breast cancer, colon cancer, or prostate cancer [48-50], although the cholesterol-cancer relationship is still unclear. High blood cholesterol and diabetes are known to be correlated with each other, yet it is unclear whether hypercholesterolemia contributes to the development of diabetes. Increasing evidence, however, suggests that high triglyceride level and low high-density lipoprotein cholesterol level are associated with an increased risk of type 2 diabetes [51-54].

Until recently, high blood cholesterol level has garnered little attention in Korea, as its prevalence was relatively low, compared to that of other risk factors. However, reports of hypercholesterolemia are increasing (Figure 9); accordingly, coronary heart disease and cholesterol-related cancers are also increasing. According to the KNHANES reports, the prevalence 
of high total cholesterol level increased from $9.9 \%$ in 1998 to $14.5 \%$ in 2011. Nevertheless, while the prevalence of hypercholesterolemia is much lower than that of hypertension, the management of hypercholesterolemia is still poor. In the 2011 KNHANES, among adults with hypercholesterolemia, the awareness rate was $43 \%$, the treatment rate was $33 \%$, and the control rate was $26 \%$ [13].

\section{CONCLUSION}

In order to reduce the burden of NCDs, comprehensive approaches across the entire disease spectrum are needed, from health promotion, primary prevention, screening of high-risk groups, and early diagnosis to better treatment and rehabilitation. An efficient and proven strategy to reducing NCD burden is risk factor modification. Major modifiable risk factors including high blood pressure, high blood cholesterol, tobacco use, alcohol consumption, and obesity are considered preventable or treatable, and exhibit great potential in reduce NCD burden.

The initial step for risk factor modification should be monitoring of prevalence and trends in risk factors. Recently, nationwide or community-based epidemiological studies have been accumulating descriptive data on NCDs and their risk factors. Over the past few decades, we observed some significant achievements in risk factor modifications among Koreans, such as improved blood pressure control and decreased smoking rate. Despite this success, hypertension and cigarette smoking still remained the most contributable factors of NCDs in the Korean population. Unfortunately, we did not observe any significant improvement in other major modifiable risk factors. Through this report, we discerned that greater attention is needed for indentifying and modifying such risk factors among subgroups of gender, age, and socioeconomic status.

Finally, the current status and trends in major modifiable risk factors reinforce the importance of prevention, detection, and treatment of risk factors in reducing the burden of NCDs on individuals and society.

\section{CONFLICT OF INTEREST}

The authors have no conflicts of interest with the material presented in this paper.

\section{REFERENCES}

1. Beaglehole R, Bonita R, Horton R, Adams C, Alleyne G, Asaria P, et al. Priority actions for the non-communicable disease crisis. Lancet 2011;377(9775):1438-1447.

2. World Health Organization. Preventing chronic diseases: a vital investment [cited 2013 Jul 7]. Available from: http://www. who.int/chp/chronic_disease_report/en.

3. World Health Organization. Global Health Observatory (GHO): deaths from NCDs [cited 2013 Jul 1]. Available from: http:// www.who.int/gho/ncd/mortality_morbidity/ncd_total/en/ index.html.

4. World Health Organization. Global Health Observatory (GHO): NCD mortality and morbidity [cited 2013 Jul 17]. Available from: http://www.who.int/gho/ncd/mortality_morbidity/en/.

5. World Health Organization. The world health report 2002: reducing risks, promoting healthy life [cited 2013 Jul 1]. Available from: http://www.who.int/whr/2002/en/index.html.

6. Jee SH, Samet JM, Ohrr H, Kim JH, Kim IS. Smoking and cancer risk in Korean men and women. Cancer Causes Control 2004; 15(4):341-348.

7. Jee SH, Suh I, Kim IS, Appel LJ. Smoking and atherosclerotic cardiovascular disease in men with low levels of serum cholesterol: the Korea Medical Insurance Corporation Study. JAMA 1999;282(22):2149-2155.

8. Jee SH, Foong AW, Hur NW, Samet JM. Smoking and risk for diabetes incidence and mortality in Korean men and women. Diabetes Care 2010;33(12):2567-2572.

9. Hur NW, Kim HC, Nam CM, Jee SH, Lee HC, Suh I. Smoking cessation and risk of type 2 diabetes mellitus: Korea Medical Insurance Corporation Study. Eur J Cardiovasc Prev Rehabil 2007;14(2):244-249.

10. Lopez AD, Mathers CD, Ezzati M, Jamison DT, Murray CJ. Measuring the global burden of disease and risk factors, 19902001. In: Lopez AD, Mathers CD, Ezzati M, Jamison DT, Murray $\mathrm{CJ}$, editors. Global burden of disease and risk factors. Washington, DC: World Bank; 2006, p. 1-13.

11. Mannino DM, Buist AS. Global burden of COPD: risk factors, prevalence, and future trends. Lancet 2007;370(9589):765773.

12. Rennard SI, Vestbo J. COPD: the dangerous underestimate of 15\%. Lancet 2006;367;(9518):1216-1219.

13. Korea Centers for Disease Control and Prevention. Korea health statistics 2011: Korea National Health and Nutrition Examination Survey (KNHANES V-2). Seoul: Ministry of Health 
and Welfare; 2012, p. 22-27, 52-59 (Korean).

14. Jung-Choi KH, Khang YH, Cho HJ. Hidden female smokers in Asia: a comparison of self-reported with cotinine-verified smoking prevalence rates in representative national data from an Asian population. Tob Control 2012;21(6):536-542.

15. Centers for Disease Control and Prevention (CDC). Alcohol-attributable deaths and years of potential life lost--United States, 2001. MMWR Morb Mortal Wkly Rep 2004;53(37):866870.

16. O'Keefe JH, Bybee KA, Lavie CJ. Alcohol and cardiovascular health: the razor-sharp double-edged sword. J Am Coll Cardiol 2007;50(11):1009-1014.

17. World Health Organization. Global status report on alcohol 2004 [cited 2013 Jul 1]. Available from: http://www.who.int/ substance_abuse/publications/global_status_report_2004_ overview.pdf.

18. Ariesen MJ, Claus SP, Rinkel GJ, Algra A. Risk factors for intracerebral hemorrhage in the general population: a systematic review. Stroke 2003;34(8):2060-2065.

19. Sturgeon JD, Folsom AR, Longstreth WT Jr, Shahar E, Rosamond WD, Cushman M. Risk factors for intracerebral hemorrhage in a pooled prospective study. Stroke 2007;38(10):27182725.

20. Bagnardi V, Blangiardo M, La Vecchia C, Corrao G. A meta-analysis of alcohol drinking and cancer risk. Br J Cancer 2001;85(11): 1700-1705.

21. Corrao G, Bagnardi V, Zambon A, La Vecchia C. A meta-analysis of alcohol consumption and the risk of 15 diseases. Prev Med 2004;38(5):613-619.

22. Babor TF, Higgins-Biddle JC, Saunders JB, Monteiro MG. The alcohol use disorders identification test: guidelines for use in primary care 2001 [cited 2013 Jul 1]. Available from: http:// whqlibdoc.who.int/hq/2001/who_msd_msb_01.6a.pdf.

23. Yoon KH, Lee JH, Kim JW, Cho JH, Choi YH, Ko SH, et al. Epidemic obesity and type 2 diabetes in Asia. Lancet 2006;368(9548): 1681-1688.

24. Lim S, Shin H, Song JH, Kwak SH, Kang SM, Yoon JW, et al. Increasing prevalence of metabolic syndrome in Korea: the Korean National Health and Nutrition Examination Survey for 1998-2007. Diabetes Care 2011;34(6):1323-1328.

25. Jung KW, Won YJ, Kong HJ, Oh CM, Seo HG, Lee JS. Cancer statistics in Korea: incidence, mortality, survival and prevalence in 2010. Cancer Res Treat 2013;45(1):1-14.

26. Park JH, Lee KS, Choi KS. Burden of cancer in Korea during 2000-2020. Cancer Epidemiol 2013;37(4):353-359.
27. Zammit $\mathrm{C}$, Liddicoat $\mathrm{H}$, Moonsie I, Makker H. Obesity and respiratory diseases. Int J Gen Med 2010;3:335-343.

28. World Health Organization. Global strategy on diet, physical activity and health [cited 2013 Jul 17]. Available from: http:// www.who.int/dietphysicalactivity/factsheet_inactivity/en/index.html.

29. Sofi F, Capalbo A, Cesari F, Abbate R, Gensini GF. Physical activity during leisure time and primary prevention of coronary heart disease: an updated meta-analysis of cohort studies. Eur J Cardiovasc Prev Rehabil 2008;15(3):247-257.

30. Lee CD, Folsom AR, Blair SN. Physical activity and stroke risk: a meta-analysis. Stroke 2003;34(10):2475-2481.

31. Thune I, Furberg AS. Physical activity and cancer risk: dose-response and cancer, all sites and site-specific. Med Sci Sports Exerc 2001;33(6 Suppl):S530-S550.

32. Lee IM, Skerrett PJ. Physical activity and all-cause mortality: what is the dose-response relation? Med Sci Sports Exerc 2001; 33(6 Suppl):S459- S471.

33. Church T. Exercise in obesity, metabolic syndrome, and diabetes. Prog Cardiovasc Dis 2011;53(6):412-418.

34. Oldridge NB. Economic burden of physical inactivity: healthcare costs associated with cardiovascular disease. Eur J Cardiovasc Prev Rehabil 2008;15(2):130-139.

35. Lee DH, Kim YM, Jekal Y, Park S, Kim KC, Naruse M, et al. Low levels of physical activity are associated with increased metabolic syndrome risk factors in korean adults. Diabetes Metab J 2013;37(2):132-139.

36. Jekal Y, Lee MK, Park S, Lee SH, Kim JY, Kang JU, et al. Association between obesity and physical fitness, and hemoglobin A1c level and metabolic syndrome in Korean adults. Korean Diabetes J 2010;34(3):182-190.

37. Neaton JD, Wentworth DN, Cutler J, Stamler J, Kuller L. Risk factors for death from different types of stroke. Multiple Risk Factor Intervention Trial Research Group. Ann Epidemiol 1993: 3(5):493-499.

38. Giroud M, Creisson E, Fayolle H, André N, Becker F, Martin D, et al. Risk factors for primary cerebral hemorrhage: a populationbased study--the Stroke Registry of Dijon. Neuroepidemiology 1995;14(1):20-26.

39. Kannel WB. Framingham study insights into hypertensive risk of cardiovascular disease. Hypertens Res 1995;18(3):181-196.

40. O'Donnell MJ, Xavier D, Liu L, Zhang H, Chin SL, Rao-Melacini $P$, et al. Risk factors for ischaemic and intracerebral haemorrhagic stroke in 22 countries (the INTERSTROKE study): a casecontrol study. Lancet 2010;376(9735):112-123. 
41. Epstein M, Sowers JR. Diabetes mellitus and hypertension. Hypertension 1992;19(5):403-418.

42. Chow WH, Gridley G, Fraumeni JF Jr, Järvholm B. Obesity, hypertension, and the risk of kidney cancer in men. $\mathrm{N}$ Engl J Med 2000;343(18):1305-1311.

43. Choi MY, Jee SH, Sull JW, Nam CM. The effect of hypertension on the risk for kidney cancer in Korean men. Kidney Int 2005; 67(2):647-652.

44. Lee SY, Kim MT, Jee SH, Im JS. Does hypertension increase mortality risk from lung cancer? A prospective cohort study on smoking, hypertension and lung cancer risk among Korean men. J Hypertens 2002;20(4):617-622.

45. Kim JS, Jones DW, Kim SJ, Hong YP. Hypertension in Korea: a national survey. Am J Prev Med 1994;10(4):200-204.

46. Kim IS, Lee YH, Suh I, Oh HC, Oh DK, Kim SJ, et al. Korean nationwide blood pressure study. Yonsei Med J 1982;23(1):1525.

47. Kannel WB. Lipids, diabetes, and coronary heart disease: insights from the Framingham Study. Am Heart J 1985;110(5): 1100-1107.

48. Kitahara CM, Berrington de González A, Freedman ND, Huxley
$\mathrm{R}$, Mok Y, Jee $\mathrm{SH}$, et al. Total cholesterol and cancer risk in a large prospective study in Korea. J Clin Oncol 2011;29(12): 1592-1598.

49. Freeman MR, Solomon KR. Cholesterol and prostate cancer. J Cell Biochem 2004;91(1):54-69.

50. Ha M, Sung J, Song YM. Serum total cholesterol and the risk of breast cancer in postmenopausal Korean women. Cancer Causes Control 2009;20(7):1055-1060.

51. Circulating cholesterol level and risk of death from cancer in men aged 40 to 69 years. Experience of an international collaborative group. JAMA 1982;248(21):2853-2859.

52. Nomura AM, Stemmermann GN, Chyou PH. Prospective study of serum cholesterol levels and large-bowel cancer. J Natl Cancer Inst 1991;83(19):1403-1407.

53. Sorlie PD, Feinleib M. The serum cholesterol-cancer relationship: an analysis of time trends in the Framingham Study. J Natl Cancer Inst 1982;69(5):989-996.

54. Williams RR, Sorlie PD, Feinleib M, McNamara PM, Kannel WB, Dawber TR. Cancer incidence by levels of cholesterol. JAMA 1981;245(3):247-252. 